MATEC Web of Conferences 9, 02002 (2013)

DOI: $10.1051 /$ matecconf $/ 20130902002$

(C) Owned by the authors, published by EDP Sciences, 2013

\title{
Fire spread modes and performance of fire stops in vented façade constructions - overview and standardization of test methods
}

\author{
Geir Jensen ${ }^{\mathrm{a}}$
}

COWI AS Trondheim, Norway

\section{INTRODUCTION}

Exterior cladding is prone to rot and fungus and the common way to prevent this is by natural vertical flow of air in gaps behind outer rainscreen panels. This provide a path for fast and hidden fire spread to fire compartments above by circumventing horizontal fire resistant compartmentation. Hidden fires may also extend vertical or horizontal to large and inaccessible areas prior to breaking through the cladding. Fire weakening of façade system integrity frequently causes flying embers and falling objects from the facade. Hidden façade fires may progress upwards several stories and may penetrate eave into attic area. Experience shows that consequences of fire in attic area often lead to severe damage or total loss of low or medium high residential blocks. Preventing fire spread in the air gaps is crucial. Existing fire stops may prevent sufficient venting or may fail to prevent fire spread, depending on the design fire exposure and construction. There is a lack of test standards to support selection of appropriate fire stop measures.

Previous research has identified modes of fire spread in vented facades. Focus is on the worst credible modes including fast upward spread. Laboratories in England and Finland conclude that velocity behind cladding is five to ten times that of fire progress on the outer surface of facades. The temperature-time curve resembles the initial part of hydrocarbon standard exposure for furnace testing. First ignition is typically abrupt flaming extending from broken windows after room flashover or spurious or deliberate ignition at air inlet of the lower part of cladding or from intermediate level balcony fires. A review is made on various fire cavity barriers as applied in several world regions for vented facades.

Where ad hoc test reports are available these are described. Reports include provisional test set ups and application tests and standard fire resistance tests. The results vary from virtually no effect or retarding effect to vented cavity barriers responding effectively as solid ones. Most products and prescribed designs apparently carry no test evidence or lack relevant test evidence. The assessments are challenged as some designs perform satisfactory to specific exposures only, while current codes and guides do not distinguish on exposure type versus fire stop type. The need for standard performance testing is urgent.

The predominant fire exposure to vented cavity barrier applications is unique in being exterior and sudden direct flaming. The barriers themselves are unique in being fully open at start of exposure, i.e. contrary to solid parts of building which are fully tight at start and until integrity fails to end the test.

The paper reports on current standardization on testing of vented fire barriers in façade assemblies.

This topic in a global perspective is addressed in a report covering national practices, codes, test methods, loss experience, test experience, real life exposures and barrier types [4].

ae-mail: gjen@cowi.com

This is an Open Access article distributed under the terms of the Creative Commons Attribution License 2.0, which permits unrestricted use, distribution, and reproduction in any medium, provided the original work is properly cited. 


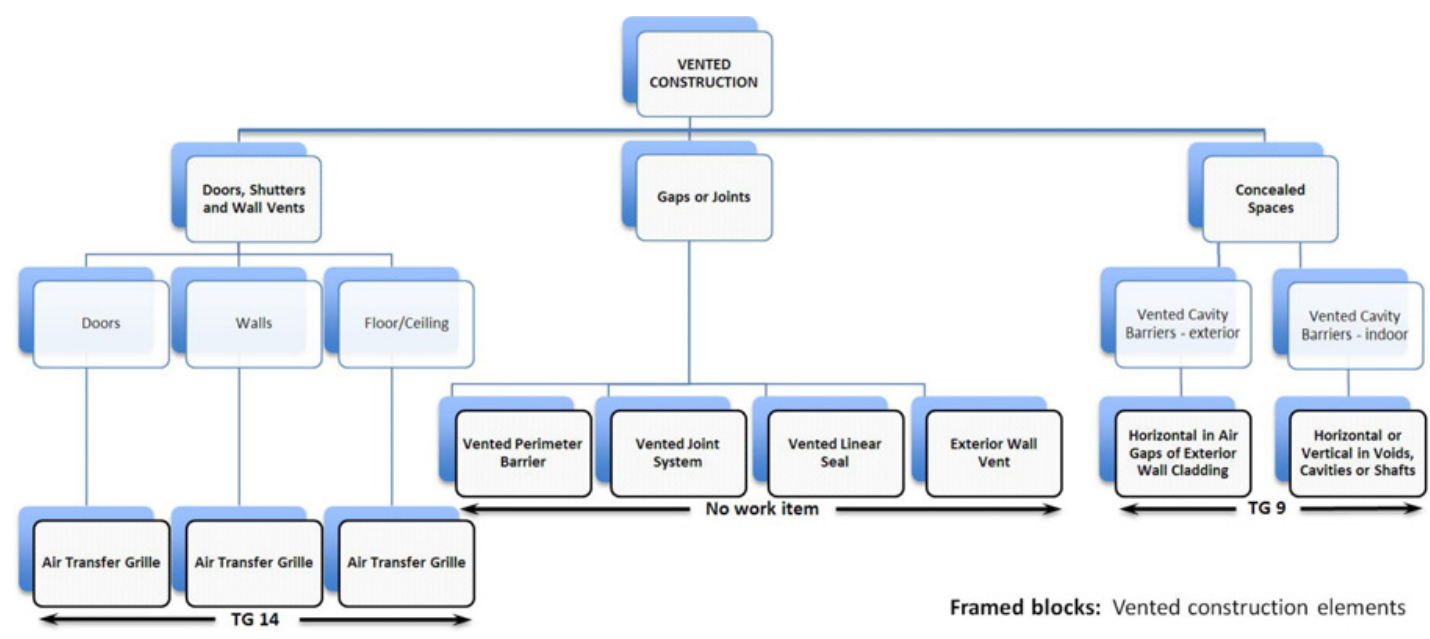

Figure 1. Vented construction: Facades may incorporate exterior vents/grilles, cavity barriers in air gaps behind the cladding perimeter barriers and eave vents.

\section{FIRE EXPOSURES}

\section{Experience and research on fire exposures to vented facades}

The requirement to naturally vent air gaps in facades and the requirement to prevent fire spread in the air gap contradict each other. Vented cavity barriers should ideally stop fire spread immediately. Most combustible debris ignites within 1-5 s when hit by flame. Unlike solid barriers of wood or mineral wool, vented barriers are open at start and designed to seal upon heat exposure. This sealing may complete from approximately $30 \mathrm{~s}$ up to $5 \mathrm{~min}$ depending on the exposure. This is not an issue with solid barriers or other fire resistant construction which are tight from start. Indeed, some test laboratories do not even record failures in furnace tests prior to $5 \mathrm{~min}$ since it is unlikely for solid fire resistant specimens to fail during the startup period. However, to most vented cavity barriers based on intumescent reaction, the opposite applies: The specimen is fully open at start so any integrity failure is most likely to occur before it becomes sealed. During the following closed state, all vented intumescent barriers tend to perform well and can easily provide 30,60 or 120 min fire resistance. Solid barriers will eventually crumple or burn through and the integrity failure occurs at the end of test only.

Room fire simulated tests such as by the standard curve for furnace tests ensure that the specimen is evenly heated over the first 1-5 min so intumescent are well expanded and sealed at the time hot gas may ignite most combustibles. Since direct flame impingement scenarios are likely in facades, room fire exposure is not relevant. The currently known full scale façade tests are not relevant to vented barriers either, since none simulate sudden breaking of window or arson liquid exposure. The time from ignition to direct flame exposure by use of wood crib, propane, sand gas burner or even liquid pool sources may be too long to simulate the direct flame attacks facades must be designed for. The greatest fire impact on the façade can be expected from direct flames, rather than from thermal radiation [16]. In contrast the ISO 13785-2:2002 [17] full scale facade test allows 4-6 min preheating of assembly and 1 minute sampling period of heat flux and temperature, so may not be used to assess vented barriers.

Attention must be drawn to the fact that failure at the start (vented barriers) is of greater concern than failure after considerable time of exposure (solid barriers). Assessing vented barriers is most important. Some barriers, either made on site or marketed as products, are shown to have inferior performance when subjected to facade fire exposures. A standard furnace test set up cannot provide a relevant direct flame exposure: Test results in England (BRE, Warrington, AFSP, Warrington for Cambridge 
Fire Research) and Norway (SINTEF pilot test) show that common vented barriers of various designs do not consistently prevent fire spread in air gaps of façade assemblies $[4,10-12,14]$.

In summary on fire exposures:

Crucial to any fire test method is fire exposure. The worst credible exposures to facades are postflashover fires breaking out of windows and liquid arson fires. These challenges vented cavity barriers the most. Slower developing exposures such as room fires and standard furnace time/temperature curve are rare if at all likely scenarios at facades. No current full scale fire test for façades provide realistic exposure to assess the fire performance of vented cavity barriers. A test method to verify adequate performance is required. The task is to realistically simulate the fast flame attacks, since all designs by definition are open at the start of fire exposure.

\section{Fire exposures to cavity barriers}

Not all applications and expected scenarios and national requirements demand the same performance. For some applications a mere delay of fire spread in cavities is sufficient prior to fire brigade intervention. Direct flame impingement is considered a low risk in some indoor applications, while it is considered most likely in others such as at breaking of windows or exterior liquid arson etc. A test method must allow for assessing performance to most common exposures and to serve most code requirements.

List below is compiled globally from regulations, guides and ad hoc tests $[4,16,17]$. These fire scenarios are considered challenging to vented barriers in facades which are in the normal open state from start:

- Initial flaming fire at vent/cavity barrier

- Back-draft

- Arson by use of liquids or pyrotechnical means (indoor/outdoor)

- Direct flaming fire (flame impingement)

- Flashover at ignition of accumulated unburnt smoke from pyrolysis or under-ventilated flaming

- Perimeter barriers (some codes require fire resistance equal to compartmentation)

- Fire spread in concealed spaces - and narrow air gaps

- Smoke from insufficient combustion seeping from a room of fire origin into adjacent cavities where it encounters oxygen and ignition sources and trigger flash fire

- Plume from exterior fire causing flash fire as smoke of insufficient combustion roll out and ignite

- Leap frog fire by exterior surface up to vented barriers in eave soffit or attic

- Leap frog fire via cavity

- Leap frog fire via exterior wall vent

- Reentrant corner: sudden horizontal flame exposure at breaking of window

- Wind-driven fire plume direct flames to suddenly hit air inlet openings in cladding or eaves.

Most combustible debris ignites within in 1-5 $\mathrm{s}$ if they are being hit directly by flames. Sustained fire on combustible surfaces may require more time, although the conditions of vented air gaps are often favorable to ignition and fire development due to narrow passages, varying distances/corners and draft.

BRE confirms that cavity fires extend rapidly and climbs to higher levels than flaming fires from a window do upon the exterior facade. BRE concludes it extends 5-10 times higher, independent of combustibility of surfaces of cavities [13] and acknowledged in introduction of ISO 13785-2:2002 [17] as well. The standard describe that direct flame impingement is prominent at façade fires. Yet, the standard prescribe 4-6 min preheating of assembly and 1 min sampling period of heat flux and temperature, rendering itself useless to assess vented barriers in the open state.

Fire progress rate in cavities has been investigated: $2-8 \mathrm{~m} / \mathrm{min}$ was recorded by VTT in realistic fire tests. Test results show that characteristics of void fire spread were close to hydrocarbon standard fire exposure curve during the first 5-6 $\min$ [7]. TÜM reports on tests with vented cavity barriers to stop or restrict rate of fire spread in exterior cavities [8]. A background report for standardization discusses 
adequate fire exposure to test open state cavity barriers [4]. Recommended means of protection are further described in a Nordic-Baltic handbook by Östman [2].

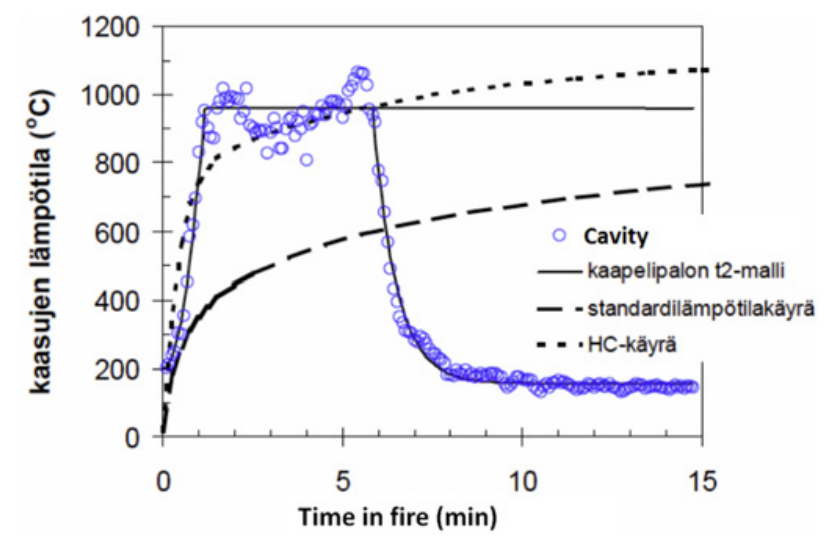

Figure 2. Characteristics of void fire spread close to hydrocarbon standard fire exposure curve during the first 5-6 $\mathrm{min}$ in test [6].

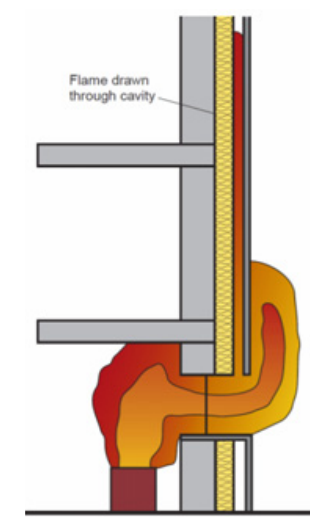

Figure 3. Flame height inside air cavity drawn 5-10 times higher than flame on exterior surface [12].

\section{PERFORMANCE REQUIREMENTS}

VTT has performed realistic testing of venting cavity barriers to assess their performance in terms of delaying the fire progress. Figure 4 shows upward spread in meters on a time scale [7]. To compare with fire resistance of solid-equivalent vented barriers note that the $\mathrm{x}$-axis coincide with performance of the latter, i.e. there is no spread above solid-equivalent vented barriers.

\section{MEANS TO PREVENT FIRE SPREAD IN VENTED FAÇADES}

Eight different designs of vented cavity barriers have been identified as being used in Europe [4]. Within any design there are multiple variations or multiple product models. A few are tested for performance in fire exposure; however these are tested by different ad hoc methods so results cannot be compared. 


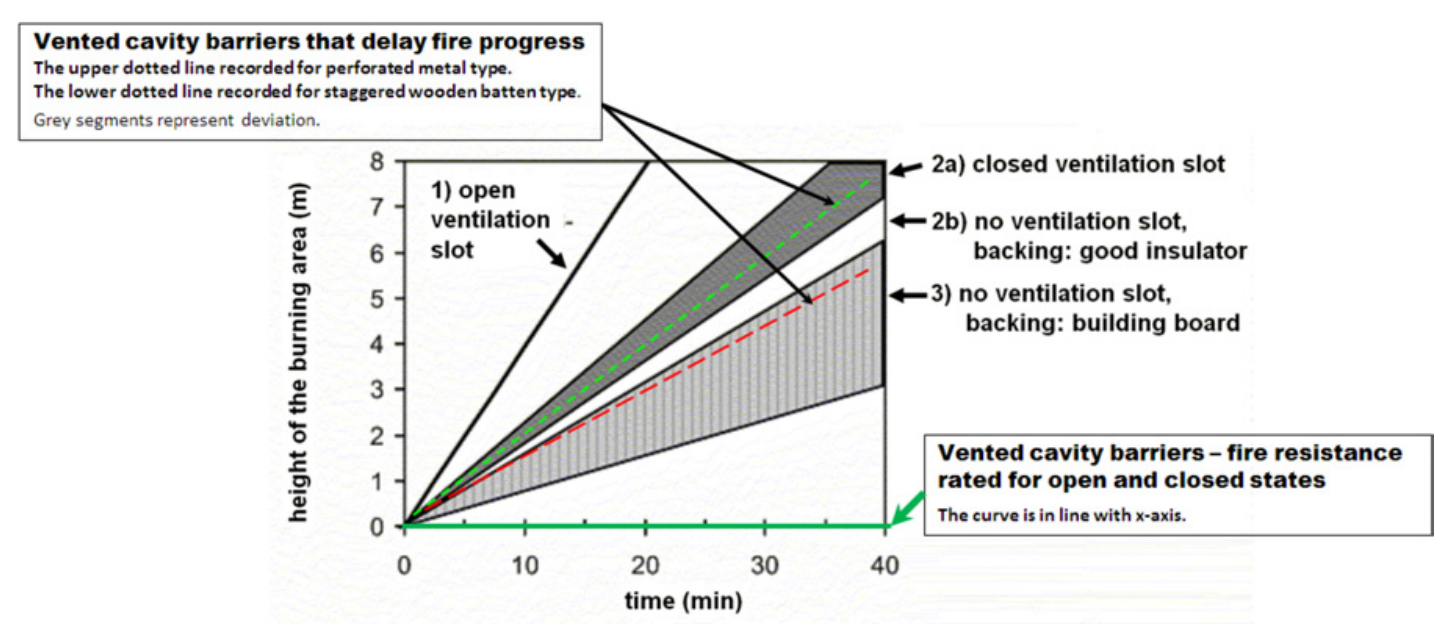

Figure 4. Extent of fire spread by time for various categories of barrier (based on [7]).

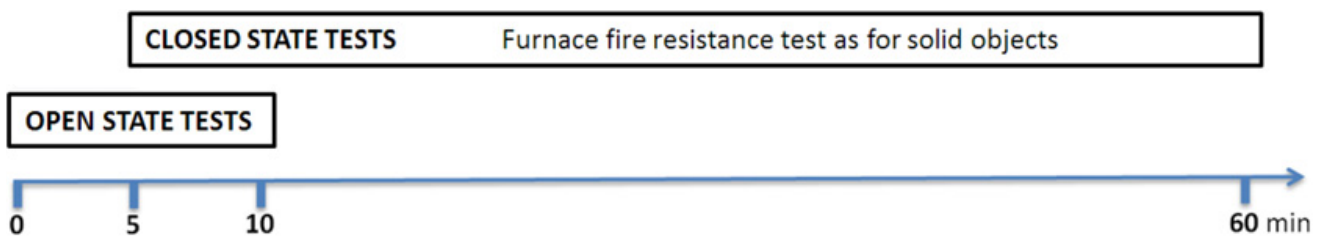

Figure 5. Tests of fire resisting performance for open state and closed state of vented cavity barriers. Standard furnace tests apply to the closed state. The dedicated test method ASTM 2912-13 [19] applies to open state performance at sudden flame attacks, as required in façade fires.

\section{Categories of vented cavity barriers in air gaps of façade cladding}

Vented facade cavity barrier categories A, B and C are sorted below by the way performances have been tested ad hoc.

A Direct flame blocking and resistance to room fire (performance equivalent to solid barrier)

These types are designed to resist exposure such as fast flaming from a window plume or from liquid arson as well as from standard furnace fire exposure.

- Narrow gap labyrinth type devices of sufficient depth plus reactive material

- Series of flame blocking baffles of sufficient spacing plus reactive material

- Devices of multiple heat sink, quenching gap and reactive elements.

B Delaying fire progress

These types are designed to resist exposures such as fast flaming from a window plume or from liquid arson or flames hitting air inlet openings in soffit of eave or in roof edges.

- Perforated metal sheet

- Series of flame blocking baffles of sufficient spacing

- Dynamic design relying on pressure gradient by gas plume velocity.

C Resistance to room fire exposure only (no open state fire stop performance)

These types are designed to resist exposure from room fire such as simulated by standard time/temperature exposures in furnaces. These types are less relevant to façade systems unless direct flame attack via windows or by liquid arson or fast progressing flame spread in the cavity can be ruled out.

- Air gap with intumescent strip 
MATEC Web of Conferences

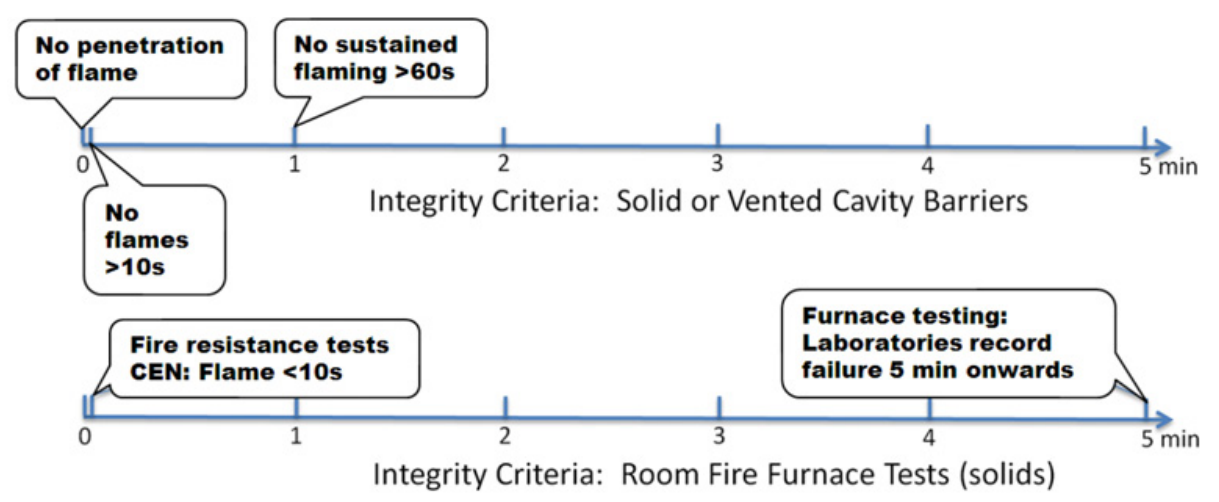

Figure 6. Integrity failure criteria compared: The ASTM E2912-13 for open state record all flame penetrations during open state from time 0 to $60 \mathrm{~s}$ to serve different thresholds set by appli- cations and codes. Standard furnace tests cannot be applied for open state testing due to no sudden flame exposure and time to calibrate conditions at start of test [4].
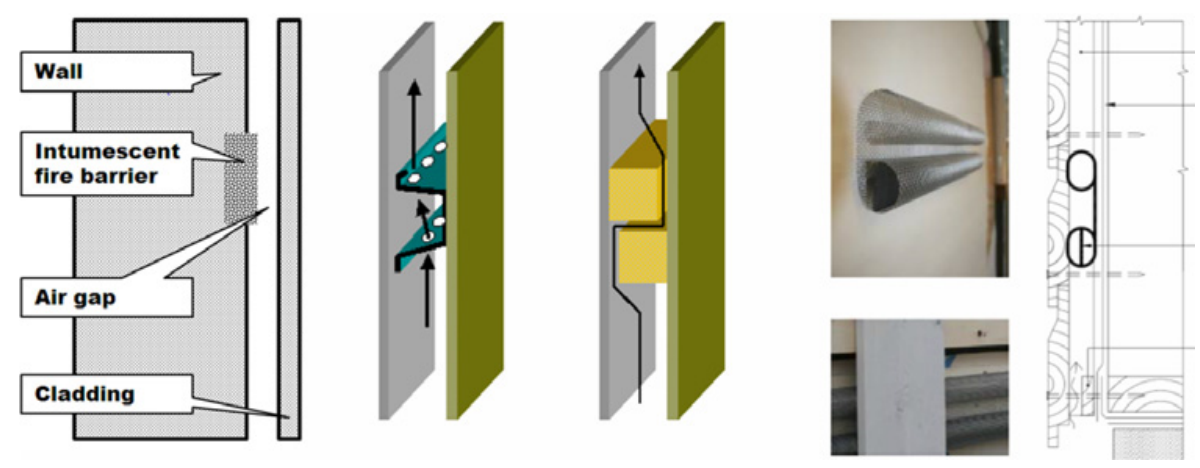

Figure 7. Various designs of vented cavity barrriers intended to prevent fire spread. From left: Intumescent strip with unprotected air gap, 2 perforated metal, 3 wood labyrinth and 4 mesh with heat sink, quenching gap and intumescent. No 1 do not offer open state fire resistance (may pass test to room fire curve, i.e. closed state only). Nos 2 and 3 restrict fire spread 4-6 min in ad hoc test. No 4 rated EI 30 (integrity and insualtion for $30 \mathrm{~min}$ ) and for open state (probing test ASTM 2912) [1,2].

\section{Other vented construction elements in facades}

Similar techniques are used for eave or gable vents and for wall vents that substitute openable windows. The latter may extend to floor-ceiling height vents and elements combined side by side to make up sections of wall that user can close or open for venting while they provide fire resistance in either state.

This kind of fire dampers in vented construction are subject to the same exterior source of fire exposure as those in air gaps behind cladding. Therefore they should be tested in the same set up, although their positions are different. In full scale tests this is accommodated by installing wall vents as in use and an eave vent as part of an eave assembly as done previously by ad hoc tests. For specimen test methods, though, fire exposures and positions should be worst case in terms of intended application. The ASTM E2912-13 [19] standard provides such a small scale test to assess open state fire resistive performance by fire dampers (vented cavity barriers). The simple open state test is designed for fire dampers in vented construction applications and pass/fail criteria are to E119/ISO 834. 


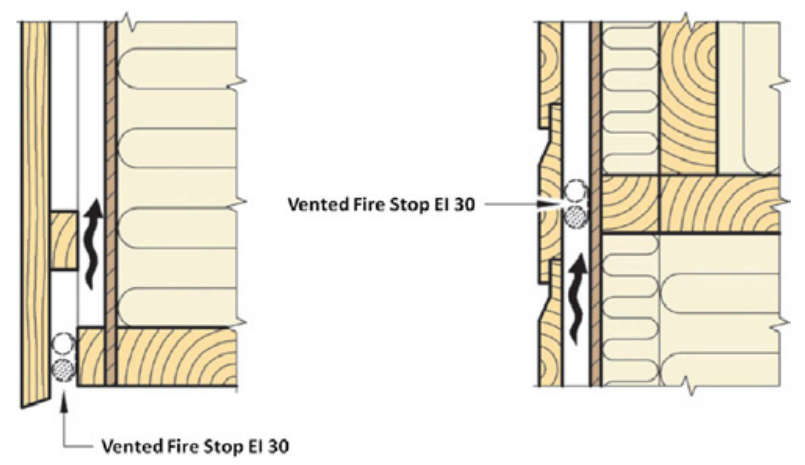

Figure 8. Recommended locations of vented cavity barriers in facades: Left: Vented cavity barrier rated EI 30 rating at bottom of vertical paneled façade. Right: Vented cavity barrier rated EI 30 at floor-wall intersection of horisontal paneled façade (Courtesy of SINTEF) [20].

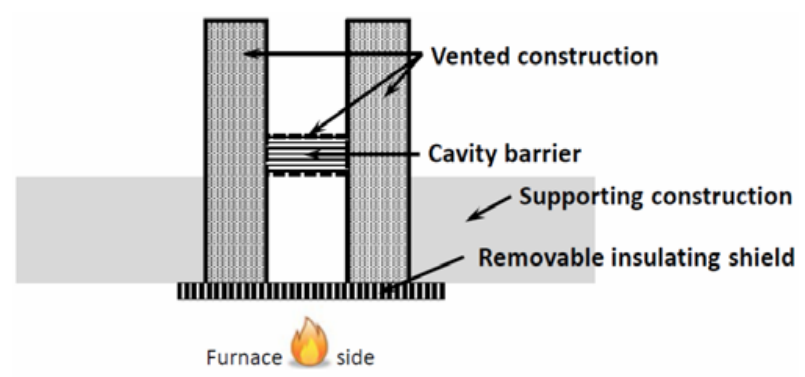

Figure 9. A proposal at CEN for small scale fire resistance test of vented cavity barriers for both open and sealed state during standard time-temperature exposure of furnace. ISO 834 pass/fail criteria apply to open and sealed state. The fixing of specimen include a removable insulating shield to replicate the sudden flame exposure from windows breaking in room fire. The shield drops at $5 \mathrm{~min}$ from start.

Categories of cavity barriers and air transfer vents that provide open state direct flame resistance:

- Labyrinth of Baffles Germany, USA

- Narrow Gap Austria, Germany, Finland, Sweden, Norway, Denmark

- Variations on Narrow Gap Austria, Germany, Denmark

- Fire Dynamic Design Finland

- Uninterrupted Fire Resistance UK, Norway, Sweden.

\section{Positioning of cavity barriers}

Vented cavity barriers in facades are usually applied horizontally as evident by Figure 8 . The same apply to manufactured façade systems such as shown in test, Figure 12.

\section{STANDARDIZATION OF TEST METHODS}

Following a survey of 15 different façade tests from 10 countries in 1988 [16]) and more added later, ISO developed the ISO 13785 parts 1 and 2 for an intermediate and a large scale test respectively, published 2002 [17]. Fire performance of vented cavity barriers was not an issue at the time. This has since changed. First, it is recognized that direct flaming exposure are typical and the speed of fire progress is 2 to $8 \mathrm{~m} / \mathrm{min}$. From start the cavity fires develop similar to the hydrocarbon standard curve 


\section{MATEC Web of Conferences}

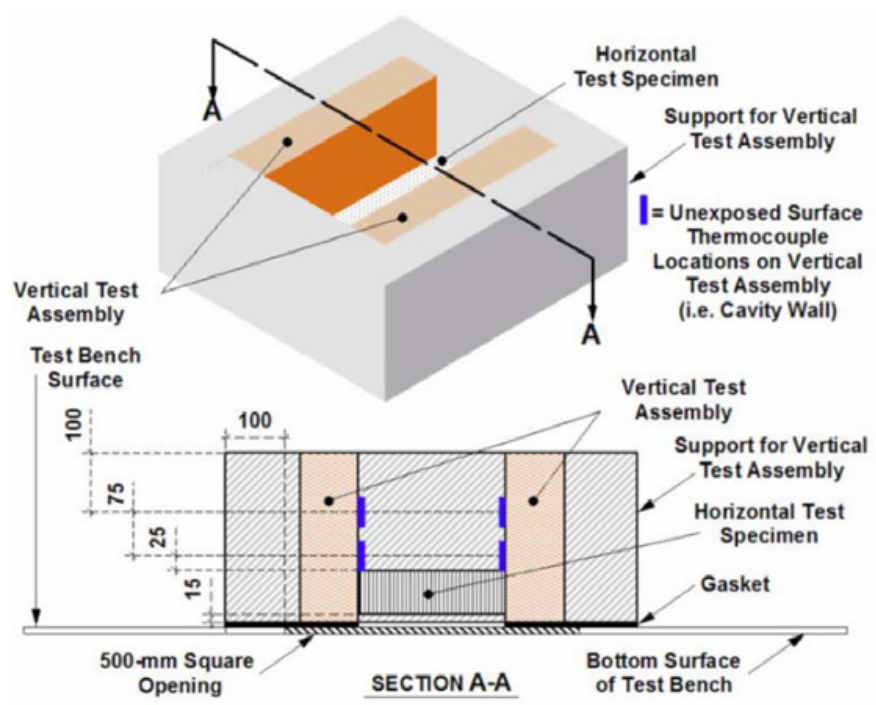

Figure 10. Vented cavity barrier installation figure of ASTM E2912-13: A Horizontal Test Specimen in Vertical Test Assembly and Unexposed Surface Thermocouple Locations is shown [19].

[6]. Second, flame height extension is governed by natural pressure differential and heat stack effects. Surprisingly flame height in air gaps do not depend on surfaces being combustible or non-combustible and extends 5-10 times higher than exterior surface flames [13]. Last, few if any vented cavity barriers were available at the time of the ISO work, however these are now in abundance and being used either separately or as part of manufactured façade systems. Some designs provide full fire resistance to direct flaming in the open state just as solid barriers while other designs delay progress of the fire.

As a consequence, ASTM issued 2013 test E2912-13 [19] for all non-mechanical fire dampers in vented construction. Equivalent terms used in Europe are vented cavity barriers and air transfer grilles.

Also a consequence, CEN Technical Committee 127 in 2012 mandated the working group on fire test methods for vented construction, i.e. vented cavity barriers and air transfer grilles, to deal with fire resistance during the initial open state of such fire barriers.

\section{CEN}

CEN TC 27 WG 1 TG 9 is developing a fire test method to evaluate the performance of vented and solid cavity barriers to prevent fire spread across sub-divisions of cavities in building construction. A single test method may be used for vented and solid barriers, or solid ones may be tested to EN 1363 . The scope initially includes any type of vented barrier typically used in facade, roof, attic or foundation. Following a TC resolution and a questionnaire to CEN member states preferences are compiled:

- Reduced scale test (full scale test methods must be retained to verify complex façade systems)

- Fire exposure to cover realistic scenarios, preferably set up by a small standard furnace

- Cavity barriers shall be installed and exposed as in use

- Vented and solid cavity barriers (resolution 778)

- In respect of diverse national regulations and applications the open state test could be optional

- Results valid for indoor or façade applications

- Results valid for type of fixed cladding and supporting material as tested only

- Failure criteria to comply with EN 1363-1 

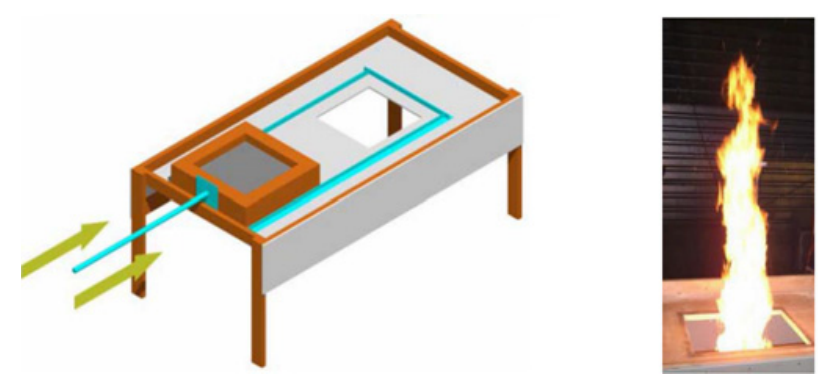

Figure 11. ASTM 2912-13: Specimen test assembly slides on test bench over a gas burner flame [19].
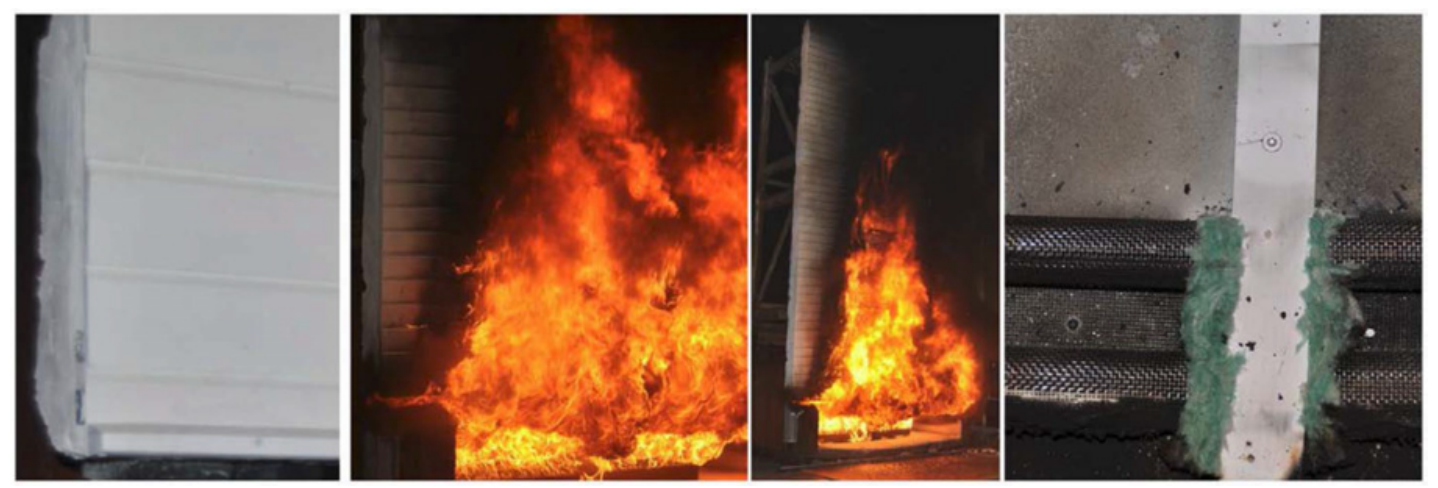

Figure 12. Facade system subjected to SP 105 full scale test [18]. From left: Façade cladding prior to test. Two images of the fire exposure. Last image show air cavity after removing the wooden cladding after test: Wall surface and wooden stud is hardly affected by fire above a solid- equivalent vented barrier rated EI 30 located where the fire hit.

- Time to failures recorded only, leaving users to decide adequacy of performance case by case.

- Test method to apply standardized fire source, reaction to fire test or fire resistance test or both.

A proposed solution at CEN is then a furnace test applying the standard curve and failure criteria of EN 1363-1. The specimen is subjected to a real life exposure and may be classified as CEN E 30 or EI 30 as applicable. Work is ongoing and no decision made.

\section{ASTM}

The ASTM E2912-13 is a standard test method to assess fire performance of vented cavity barriers (US: non-mechanical fire dampers) in the open state. Typically, a specimen has passed a fire resistance test so this is additional test to verify that the product is fit for use where direct flame impingement is a risk. The method subjects specimen to sustained flame by sliding it quickly over a sand gas burner. The standard describes assemblies for both vertical and horizontal specimens and for any kind of uniform specimen used in vented construction. The term vented construction encompasses floor, wall, roof, ceiling, joint, door or wall cavity, crawl space, air gap or other used for venting, including ductless ventilation.

\section{Full scale facade tests}

The SP FIRE 105, BS 8414 and LPCB 1181 are full scale facade tests. These mimic real life exposure well as worst credible severity, except for vented air gap barriers during open state prior to sealing. 


\section{MATEC Web of Conferences}

None of the tests simulate sudden breaking of window or arson liquid exposure. The time from ignition to direct flame exposure by wood crib and even by propane or liquid pool sources may be too long to simulate the fast flame attacks facades must be designed for. The greatest fire impact on the façade can be expected from direct flames, rather than from thermal radiation [16]. In contrast the ISO 13785-2: 2002 [17] full scale facade test allows 4-6 min preheating of assembly and 1 minute sampling period of heat flux and temperature, so may not be used to assess vented barriers. Full scale tests are cost prohibitive for testing of standard cavity barriers as well.

A possibility is to retain full scale tests as they are and rely on the additional test ASTM 291213 [19], or rely on an equivalent CEN standard to be developed for vented cavity barriers in façade assemblies. Another possibility is to amend full scale tests to include an insulated shield at the fire outlet to prevent preheating of assembly and by removing it to simulate breaking of a window. Babrauskas suggests that artificial retracted windows in the SP FIRE 105 test to be replaced by real window details as well [16].

\section{CLASSIFICATION}

The desired performance of vented cavity barriers is commonly fire resistance in terms of integrity and insulation for 15, 20 or 30 minutes, i.e. vented barriers should perform as solid barriers when subjected to relevant facade fires. They may indeed pass furnace fire resistance tests and obtain integrity and insulation ratings as solid specimens. However, vented barriers are not fit for use without having assessed their open state performance to realistic exterior exposures. Classification systems need to address this.

\section{CONCLUSION}

The common fire exposures that challenges vented cavity barriers used in façade systems today are not found to be adequately simulated by any full scale fire test. To assess the performance under sudden direct flame impingement one need to perform an additional test. Currently the bench scale method of ASTM E2912-13 provides this, as being dedicated to open state fire resistive performance of vented fire barriers.

In order to do a single test only it is proposed to re-develop an existing full scale façade system test to include adequate open state fire exposure. Alternatively, during work at CEN on a small scale method for vented and solid cavity barriers, it is proposed regarding Europe to design adequate open state exposure so a single test can apply to both solid and vented barriers for use in facades or elsewhere.

\section{References}

[1] Östman, Mikkola, Stein, Frangi, König, Dhima, Hakkarainen, Bregulla. "Fire safety in timber buildings. Technical guideline for Europe". SP Technical Research Institute of Sweden. Report 2010:19. 2010.

[2] Östman, B et al: "Brandsäkra trähus. Version 3". Nordic-Baltic Handbook. SP Technical Research Institute of Sweden. 2012.

[3] Steen-Hansen, Wighus, Jensen, Steiro, Larsen:"Byen brenner. Hvordan forhindre storbranner $i$ tett verneverdig trehusbebyggelse. Røros som eksempel” SINTEF Report NBL A03197.2004.

[4] Jensen and Tamim: "Addressing Fire Risks of Air Transfer Openings". ASTM. Report in support of the development of a Standard Test Method for Fire Test of Vented Construction. 2011.

[5] Hakkarainen; Oksanen: Fire Safety Assessment of Wooden Facades. Fire and Materials 26. 2002.

[6] Hietaniemi J, Vaari J, Hakkarainen T, Huhta I, Jumppanen U-M, Korhonen T, Kouhia I, Siiskonen $\mathrm{J}$ and Weckman H: Fire safety of cavity spaces - Characteristics of fires in building voids, their structural prevention and extinguishing (Finnish), VTT Research Notes 2249. Espoo 2004. 
[7] Ryyniinen and Mikkola. Fire safety of cavity spaces - Characteristics of fires in building voids and their structural prevention. Translation in parts of VTT Research Notes 2249, 2009.

[8] Stein R, Werther N, Winter S. Konstruktionskatalog fiir Gebäude in Holzbauweise unter Berücksichtigung bauordnungsrechtlicher und versicherungstechnischer Aspekte. Technische Universität München. Planned for publication, 2013.

[9] Bassett and McNeil. Ventilating Wall Cavities above Windows. Journal of Building Physics. 2009.

[10] Jensen, Landro, Log, Stenstad, Grimwood, Vik, Bragstad. Venting in Fire Rated Wooden Construction. Proceedings Interflam 2004, p. 597-602.

[11] Tamim A, Stolen R. Fire Containment By Vent Opening Protectives In The Open State. Proceedings lnterflam 2010, p. 1783-1792.

[12] Colwell, Bregulla, Cullinan. Fire Safety of External Timber Wall Facades. Proceedings Interflam 2007, p. 771-776. (paper based on Colwell, Martin Fire performance of external thermal insulation for walls of multi-storey buildings. BRE and FRS. 2nd Edition. 2003).

[13] Colwell and Baker: Fire Performance of External Thermal Insulation for Walls of Multistorey Buildings. BRE Trust. 3rd edition 2013.

[14] Stolen, R. Ad hoc test of fire resistance of air transfer dampers during the open state of exposure to fire. SINTEF 2010.

[15] Bong, F: Fire Spread on Exterior Walls. University of Canterbury. NZ. ISSN 1173-5996. 2000.

[16] Babrauskas, Vytenis: Façade Fire Tests: Towards an International Test Standard. Fire Technology Third Quarter 1996.

[17] Standards ISO 13785-1 and ISO 13785-2 Reaction-to-fire tests for facades. 2002.

[18] Standard SP FIRE 105 External wall assemblies and facade claddings reaction to fire. 1994.

[19] Standard ASTM E2912-13 Standard Test Method for Fire Test of Non-Mechanical Fire Dampers Used in Vented Construction. 2013.

[20] SINTEF Byggforsk. Byggforskserien 520.308 Yttervegger og tak $i$ trehus med 30 minutters brannmotstand. 2010. 